\title{
Silencing NKD2 by promoter region hypermethylation promotes gastric cancer invasion and metastasis by up-regulating SOX18 in human gastric cancer
}

\author{
Yan Jia ${ }^{1,2, *}$, Baoping $\mathrm{Cao}^{1,3, *}$, Yunsheng Yang${ }^{1}$, Enqiang Linghu ${ }^{1}$, Qimin Zhan ${ }^{4}$, \\ Youyong Lu ${ }^{5}$, Yingyan $\mathbf{Y u}^{6}$, James G. Hermann, Mingzhou Guo ${ }^{1}$ \\ ${ }^{1}$ Department of Gastroenterology \& Hepatology, Chinese PLA General Hospital, Beijing 100853, China \\ ${ }^{2}$ Department of Breast Oncology, Tianjin Medical University Cancer Institute and Hospital, National Clinical Research Center \\ for Cancer, and Key Laboratory of Cancer Prevention and Therapy, Tianjin 300060, China \\ ${ }^{3}$ Medical College of NanKai University, Tianjin 300071, China \\ ${ }^{4}$ State Key Laboratory of Molecular Oncology, Cancer Institute and Hospital, Chinese Academy of Medical Sciences \& Peking \\ Union Medical College, Beijing 100021, China \\ ${ }^{5}$ Laboratory of Molecular Oncology, Key Laboratory of Carcinogenesis and Translational Research (Ministry of Education), \\ Peking University Cancer Hospital/Institute, Beijing 100142, China \\ ${ }^{6}$ Shanghai Ruijin Hospital, Shanghai Jiao Tong University School of Medicine, Shanghai 200240, China \\ ${ }^{7}$ The Hillman Cancer Center, University of Pittsburgh Cancer Institute, Pittsburgh, PA 15213, USA \\ *These authors have contributed equally to this work \\ Correspondence to: \\ Mingzhou Guo, e-mail: mzguo@hotmail.com \\ James G. Herman, e-mail: Hermanj3@upmc.edu \\ Keywords: NKD1, NKD2, SOX18, DNA methylation, gastric cancer
}

Received: April 23, $2015 \quad$ Accepted: September 02, $2015 \quad$ Published: September 14, 2015

\section{ABSTRACT}

Naked cuticle homolog2 (NKD2) is located in chromosome 5p15.3, which is frequently loss of heterozygosity in human colorectal and gastric cancers. In order to understand the mechanism of NKD2 in gastric cancer development, 6 gastric cancer cell lines and 196 cases of human primary gastric cancer samples were involved. Methylation specific PCR (MSP), gene expression array, flow cytometry, transwell assay and xenograft mice model were employed in this study. The expression of NKD1 and NKD2 was silenced by promoter region hypermethylation. NKD1 and NKD2 were methylated in $11.7 \%(23 / 196)$ and $53.1 \%(104 / 196)$ in human primary gastric cancer samples. NKD2 methylation is associated with cell differentiation, TNM stage and distant metastasis significantly (all $P<0.05$ ), and the overall survival time is longer in NKD2 unmethylated group compared to NKD2 methylated group $(P<0.05)$. Restoration of NKD2 expression suppressed cell proliferation, colony formation, cell invasion and migration, induced $\mathrm{G2} / \mathrm{M}$ phase arrest, and sensitized cancer cells to docetaxel. NKD2 inhibits SOX18 and MMP-2,7,9 expression and suppresses BGC823 cell xenograft growth. In conclusion, NKD2 methylation may serve as a poor prognostic and chemo-sensitive marker in human gastric cancer. NKD2 impedes gastric cancer metastasis by inhibiting SOX18.

\section{INTRODUCTION}

Almost one million new cases of stomach cancer were estimated to have occurred in 2012, making it the fifth most common malignancy in the world. More than $70 \%$ of cases occur in developing countries and half of the world's total cases occur in Eastern Asia [1]. Etiologically, gastric cancer is associated with the combined effects of environmental factors and susceptible genetic variants, including the accumulation of genetic and epigenetic alterations [2-4]. H. pylori infection, smoking, and ingestion of salt-preserved foods and salt are regarded as 
risk factors for gastric cancer [5]. Approximately 1-3\% of gastric cancer is hereditary diffuse gastric cancer. In roughly $30 \%$ of familial gastric cancers, a germline mutation in one allele of the E-cadherin gene $(\mathrm{CDH} 1)$ can be identified. Inactivation of the second allele occurs either by mutation or hypermethylation. The estimated life-time risk of developing gastric cancer in carriers of a $C D H 1$ mutation is $67 \%$ in men and $83 \%$ in women [5-7]. According to a recent study that performed targeted deep sequencing in 167 cases of gastric cancer, TP53 was among the most commonly mutated genes (35\%). Other frequently mutated genes identified were PI3KCA (6\%), CTNNB1 (5\%), KRAS (5\%) and SMAD4 (4\%) [8]. A number of tumor suppressor genes, such as $h M L M 1, p 14$, p15, p16, GSTP1, RASSF1, COX-2, APC, CDH1, CDH4, DAP-K, THBS1, TIMP-3, RAR, MGMT, CHFR, DCC, RUNX3, TSLC1, BCL2L10, IRX1, CMDM and UCHL1, are frequently silenced by hypermethylation in gastric cancer [9-12].

Naked cuticle homolog1 (NKD1) and 2 (NKD2) are two mammalian orthologs of drosophila naked cuticle $[13,14]$. NKD1 is located in human chromosome 16q12.1, which has frequent loss of heterozygosity in human breast and hepatocellular carcinoma [15-17]. NKD2 is located in chromosome 5p15.3, and loss of heterozygosity is frequently found in this region in colorectal and gastric cancer $[18,19]$. In both zebrafish and mice, NKD inhibits canonical and non-canonical Wnt signaling [14, 20, 21]. Myristoylation of mammalian NKD2, but not NKD1, interacts with the cytoplasmic tail of TGF- $\alpha$ and accelerates TGF- $\alpha$ processing and cellsurface delivery [22]. In addition, overexpression of TGF- $\alpha$ protects the NKD2 protein from rapid ubiquitinmediated proteasomal degradation in an EGFRindependent manner in HEK293 cells [23]. NKD2 has been reported to suppress tumor growth and metastasis in osteosarcoma [24]. In this study, we focused on the epigenetic changes and mechanisms of NKD2 in human gastric carcinogenesis.

\section{RESULTS}

\section{NKD1 and NKD2 expression are silenced by promoter region hypermethylation in gastric cancer cell lines}

To explore the regulation mechanisms of the $N K D$ gene family in gastric cancer, the expression levels of NKD1 and NKD2 were examined by semi-quantitative RT-PCR. Loss of NKD1 expression was observed in BGC823 and MGC803 cells, and NKD1 expression was found in SGC7901, AGS, N87 and MKN45 cells. Loss of NKD2 expression was found in BGC823, MGC803 and AGS cells, and low level expression of NKD2 was detected in N87 cells. The expression of NKD2 was observed in SGC7901 and MKN45 cells (Figure 1A). Promoter region methylation was detected by methylation-specific PCR (MSP). NKD1 was completely methylated in BGC823 and MGC803 cells, and it was unmethylated in SGC7901, AGS, N87 and MKN45 cells. NKD2 was found to be completely methylated in BGC823, MGC803 and AGS cells, partially methylated in N87 cells, and unmethylated in SGC7901 and MKN45 cells (Figure 1B). The above results demonstrate that loss or reduction of NKD expression is correlated with promoter region hypermethylation in human gastric cancer cells. Representative bisulfite sequencing results are shown in Figure 1C. NKD1 was densely methylated in the promoter region in BGC823 cells and unmethylated in MKN45 cells. NKD2 was densely methylated in BGC823, partially methylated in N87 and unmethylated in MKN45 cells and normal gastric mucosa. These results further validated the efficiency of the MSP primers and the density of promoter region methylation.

To further determine whether expression levels of the $N K D$ genes were regulated by promoter region methylation, we treated cells with 5-aza-2'-deoxycytidine (DAC), a DNA methylation transferase (DNMTs) inhibitor that induces re-expression of methylated genes through demethylation [25, 26]. Re-expression of NKD1 was induced in BGC823 and MGC803 cells. No NKD1 expression changes were detected in the unmethylated SGC7901, AGS, N87 and MKN45 cell lines. Re-expression of NKD2 was induced in BGC823, MGC803 and AGS cells. Increased expression of NKD2 was observed in N87 cells. No NKD2 expression changes were demonstrated in the unmethylated SGC7901 and MKN45 cells. These results suggest that the expression levels of NKD1 and NKD2 are regulated by promoter region methylation in human gastric cancer cells.

\section{NKD2 methylation is related to gastric cancer progression and metastasis and may serve as a poor prognostic predictor}

Methylation of NKD1 and NKD2 was examined in 196 cases of primary gastric cancer and 28 cases of normal gastric mucosa. No methylation was found in these genes in normal human gastric mucosa (Figure 2A). NKD1 was methylated in $11.7 \%(23 / 196)$ of human gastric cancer, and methylation of $N K D 1$ was not associated with cell differentiation, TNM stage, distant metastasis, age, gender, tumor size, location and vessel invasion (all $P>0.05$, Table 1). As shown in Figure 2C, no significant difference was found between the NKD1 unmethylation and methylation groups for overall survival time (log-rank, $P=0.26$ ). The above results demonstrate that $N K D 1$ methylation may not play an important role in gastric carcinogenesis and progression. NKD2 was methylated in $53.1 \%(104 / 196)$ of human primary gastric cancer samples 

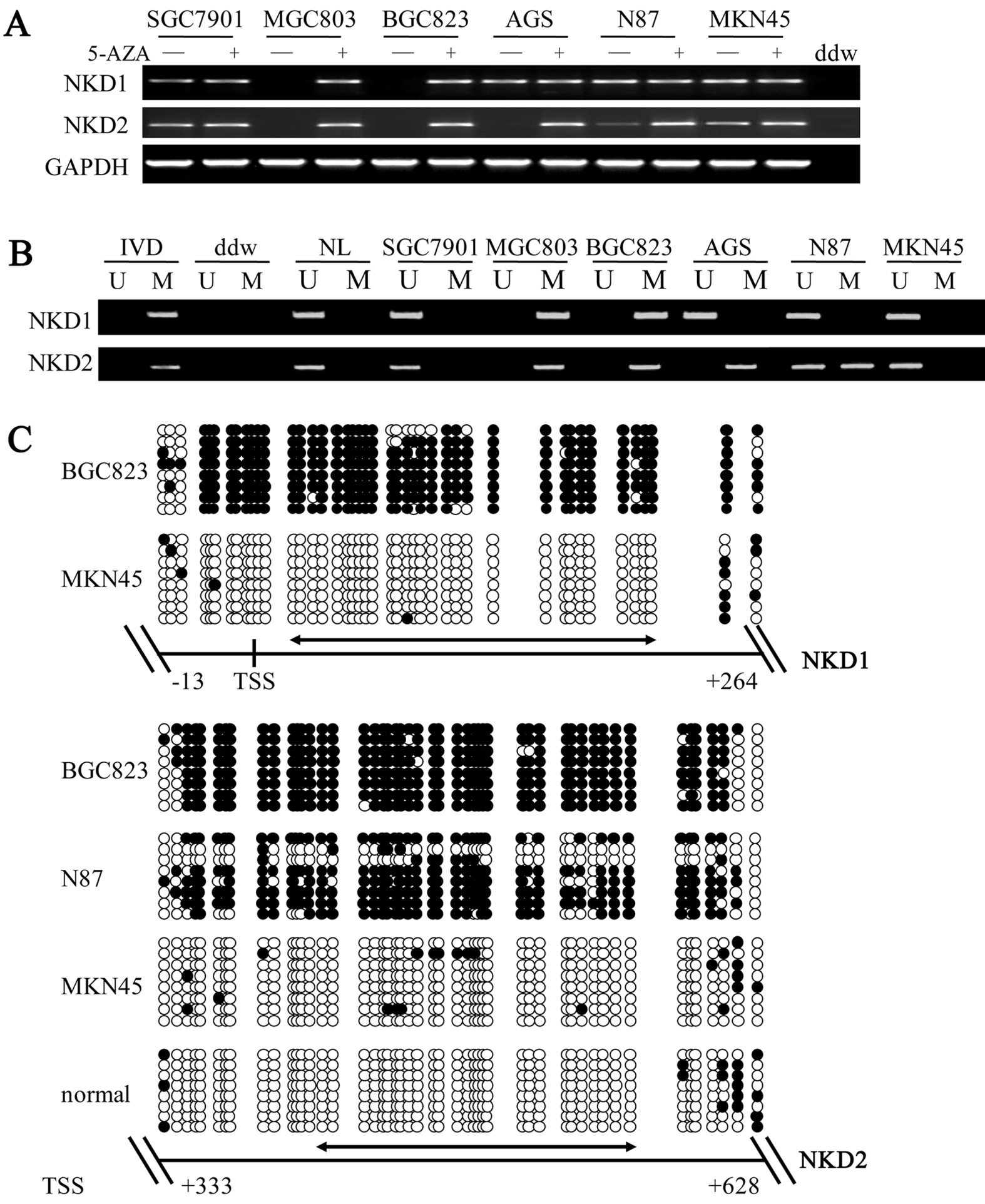

Figure 1: The expression of NKD1 and NKD2 and their methylation status in human gastric cancer cells. A. Semiquantitative RT-PCR shows NKD1 and NKD2 expression levels in gastric cancer cell lines. SGC7901, MGC803, BGC823, AGS, N87 and MKN45 are gastric cancer cell lines. 5-AZA: 5-aza-2'-deoxycytidine; GAPDH: internal control of RT-PCR; ddw: double distilled water. $(-)$ : absence of 5-AZA; (+): presence of 5-AZA. B. MSP results of NKD1 and NKD2 in gastric cancer cell lines. U: unmethylated alleles; M: methylated alleles; IVD: in vitro methylated DNA, serves as methylation control; NL: normal peripheral lymphocytes DNA, serves as unmethylation control; ddw: double distilled water. C. BSSQ results of NKD1 in BGC823 and MKN45 cells and NKD2 in BGC823, N87, MKN45 cells and normal gastric mucosa. Upper portion of double-headed arrow: MSP PCR product size was 194 bp in NKD1 and bisulfite sequencing focused on a $277 \mathrm{bp}$ region of the $\mathrm{CpG}$ island (from -13 to +264 ) around the NKD1 transcription start site. Lower portion of double-headed arrow: MSP PCR product spanned 166 bp in NKD2. Bisulfite sequencing focused on a 295 bp region of the CpG island ( +333 bp to +628 bp) downstream of the NKD2 transcription start site. Filled circles: methylated CpG sites, open circles: unmethylated CpG sites. TSS: transcription start site; normal: normal gastric mucosa. 


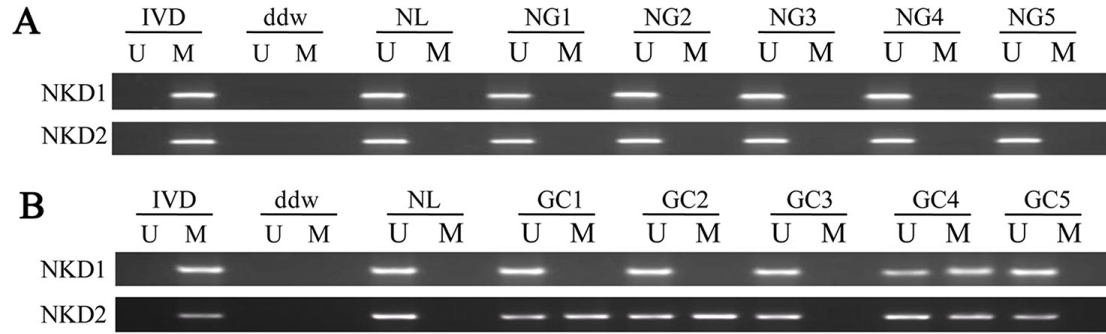

C
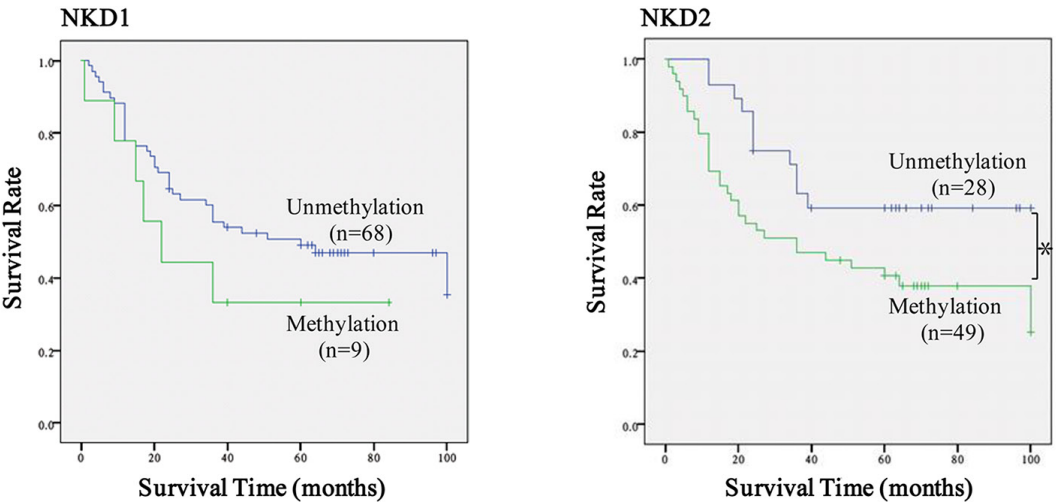

D

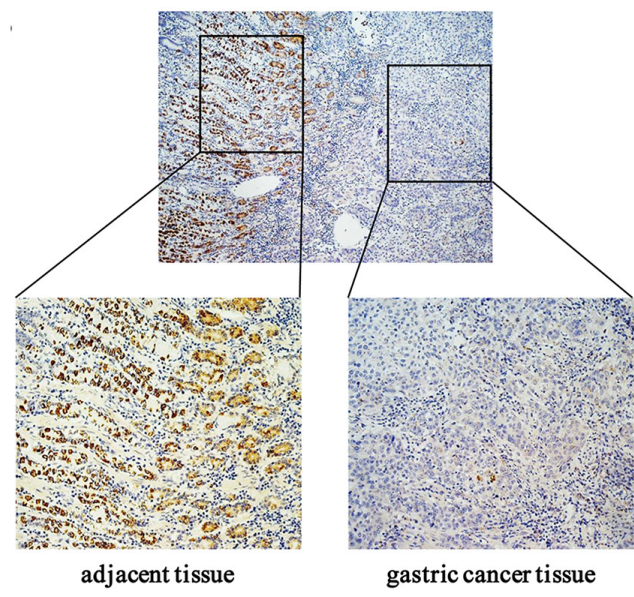

$\mathrm{E}$

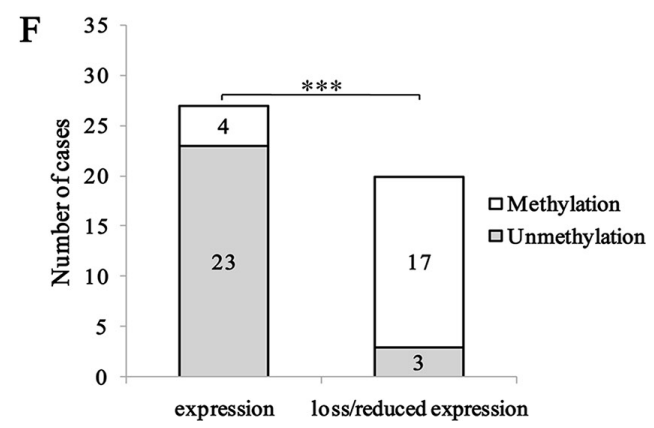

Figure 2: Methylation and expression status of $N K D 2$ in primary gastric cancer and their prognostic value. A. MSP results of NKD1 and NKD2 in normal gastric mucosa. NG: normal gastric mucosa. B. Representative results of MSP for NKD1 and NKD2 in primary gastric cancer samples. GC: primary gastric cancer samples. C. The survival of gastric cancer patients in methylated and unmethylated $N K D 1$ and $N K D 2$ cases. Methylation of $N K D 2$ was associated with poor prognosis $\left({ }^{*} P<0.05\right)$. D. Representative IHC results show NKD2 expression in gastric cancer and adjacent tissue samples (upper: $\times 40$; lower: $\times 200$ ). E. NKD2 expression scores are shown as box plots, horizontal lines represent the median score; the bottom and top of the boxes represent the 25th and 75th percentiles, respectively; vertical bars represent the range of data. Expression of NKD2 was significantly different between adjacent tissue and gastric cancer tissue in 47 -matched primary gastric cancer samples. $* P<0.05$. F. The expression of NKD2 and DNA methylation status is shown as a bar diagram. Reduced expression of NKD2 was significantly associated with promoter region hypermethylation. ${ }^{* * *} P<0.001$. 
Table 1: Clinical factors and NKD1 methylation in 196 cases of gastric cancer samples

\begin{tabular}{|c|c|c|c|c|}
\hline \multirow[t]{2}{*}{ Clinical factor } & \multirow[t]{2}{*}{ No. } & \multicolumn{2}{|c|}{ NKD1 methylation status } & \multirow[t]{2}{*}{$P^{*}$ value } \\
\hline & & $\begin{array}{c}\text { Methylated } n=23 \\
(11.7 \%)\end{array}$ & $\begin{array}{c}\text { Unmethylated } \\
n=173(87.2 \%)\end{array}$ & \\
\hline \multicolumn{5}{|l|}{ Age (year) } \\
\hline$<50$ & 40 & 3 & 37 & $P=0.5109$ \\
\hline$\geq 50$ & 156 & 20 & 136 & \\
\hline \multicolumn{5}{|l|}{ Gender } \\
\hline Male & 138 & 16 & 122 & $P=0.9249$ \\
\hline Female & 58 & 7 & 51 & \\
\hline \multicolumn{5}{|l|}{ Tumor Size (cm) } \\
\hline$\leq 5$ & 110 & 13 & 97 & $P=0.9672$ \\
\hline$>5$ & 86 & 10 & 76 & \\
\hline \multicolumn{5}{|l|}{ Tumor Location } \\
\hline Upper & 42 & 3 & 39 & $P=0.3624$ \\
\hline Middle & 55 & 9 & 46 & \\
\hline Lower & 99 & 11 & 88 & \\
\hline \multicolumn{5}{|l|}{ Differentiation } \\
\hline Well & 10 & 0 & 10 & $P=0.1596$ \\
\hline Moderate & 57 & 4 & 53 & \\
\hline Poor & 129 & 19 & 110 & \\
\hline \multicolumn{5}{|l|}{ TNM Stage } \\
\hline I & 17 & 1 & 16 & $P=0.5921$ \\
\hline II & 51 & 8 & 43 & \\
\hline III & 101 & 10 & 91 & \\
\hline IV & 27 & 4 & 23 & \\
\hline \multicolumn{5}{|c|}{ Distant metastasis } \\
\hline M0 & 174 & 20 & 154 & $P=0.9542$ \\
\hline M1 & 22 & 3 & 19 & \\
\hline \multicolumn{5}{|l|}{ Vessel Invasion } \\
\hline Negative & 115 & 14 & 101 & $P=0.9982$ \\
\hline Positive & 81 & 9 & 72 & \\
\hline
\end{tabular}

* $P$ values are obtained from chi-square test, significant difference, $P<0.05$

(Figure 2B), and methylation of NKD2 was significantly associated with the degree of cell differentiation, TNM stage and distant metastasis (all $P<0.05$, Table 2). Meanwhile no association was found between NKD2 methylation and age, gender, tumor size, location and vessel invasion. As shown in Figure $2 \mathrm{C}$, the overall survival was longer in the $N K D 2$ unmethylation group compared to the NKD2 methylation group $(P<0.05)$, suggesting that $N K D 2$ methylation is related to tumor malignancy, progression and metastasis, and it may serve as a poor prognostic predictor in human gastric cancer. While, the COX regression analysis indicated that NKD2 methylation is not an independent prognostic factor in gastric cancer.

As NKD1 methylation did not appear to be a major event in human gastric cancer, we mainly focused on the mechanisms of NKD2 in gastric carcinogenesis. The expression of NKD2 was evaluated by IHC in 47 cases of available matched gastric cancer and adjacent tissue 
Table 2: Clinical factors and NKD2 methylation in 196 cases of gastric cancer samples

\begin{tabular}{|c|c|c|c|c|}
\hline \multirow[t]{2}{*}{ Clinical factor } & \multirow[t]{2}{*}{ No. } & \multicolumn{2}{|c|}{ NKD2 methylation status } & \multirow[t]{2}{*}{$P^{*}$ value } \\
\hline & & $\begin{array}{c}\text { Methylated } n=104 \\
(53.1 \%)\end{array}$ & $\begin{array}{c}\text { Unmethylated } n=92 \\
(46.9 \%)\end{array}$ & \\
\hline \multicolumn{5}{|l|}{ Age (year) } \\
\hline$<50$ & 40 & 22 & 18 & $P=0.7830$ \\
\hline$\geq 50$ & 156 & 82 & 74 & \\
\hline \multicolumn{5}{|l|}{ Gender } \\
\hline Male & 138 & 71 & 67 & $P=0.4855$ \\
\hline Female & 58 & 33 & 25 & \\
\hline \multicolumn{5}{|l|}{ Tumor Size $(\mathrm{cm})$} \\
\hline$\leq 5$ & 110 & 63 & 47 & $P=0.1815$ \\
\hline$>5$ & 86 & 41 & 45 & \\
\hline \multicolumn{5}{|l|}{ Tumor Location } \\
\hline Upper & 42 & 22 & 20 & $P=0.7396$ \\
\hline Middle & 55 & 27 & 28 & \\
\hline Lower & 99 & 55 & 44 & \\
\hline \multicolumn{5}{|l|}{ Differentiation } \\
\hline Well & 10 & 1 & 9 & $P=0.0146<0.05$ \\
\hline Moderate & 57 & 34 & 23 & \\
\hline Poor & 129 & 69 & 60 & \\
\hline \multicolumn{5}{|l|}{ TNM Stage } \\
\hline I & 17 & 13 & 4 & $P=0.0297<0.05$ \\
\hline II & 51 & 24 & 27 & \\
\hline III & 101 & 48 & 53 & \\
\hline IV & 27 & 19 & 8 & \\
\hline \multicolumn{5}{|c|}{ Distant metastasis } \\
\hline M0 & 174 & 88 & 86 & $P=0.0498<0.05$ \\
\hline M1 & 22 & 16 & 6 & \\
\hline \multicolumn{5}{|l|}{ Vessel Invasion } \\
\hline Negative & 115 & 56 & 59 & $P=0.1445$ \\
\hline Positive & 81 & 48 & 33 & \\
\hline
\end{tabular}

$* P$ values are obtained from chi-square test, significant difference, $P<0.05$

samples. The expression of NKD2 was apparently reduced in 20 cases of gastric cancer tissue samples compared to adjacent tissue samples (Figure 2D and 2E). In 20 cases of loss/reduced expression of NKD2 cancer samples, 17 cases were methylated. In 27 cases of NKD2 expressed cancer samples, 4 cases were methylated. Loss/reduced expression of NKD2 was related to promoter region hypermethylation $(P<0.001$, Figure $2 \mathrm{~F})$. These results indicate that
NKD2 expression may be regulated by promoter region methylation in human primary gastric cancer.

\section{Restoration of NKD2 expression suppresses cell growth in BGC823 and MGC803 cells}

The effect of NKD2 on cell proliferation was evaluated by the MTT assay in BGC823 and MGC803 
cells. The OD value was $0.352 \pm 0.007$ vs. $0.304 \pm 0.011$ $(P<0.05)$ in BGC823 cells and $0.587 \pm 0.020$ vs 0.525 $\pm 0.012(P<0.05)$ in MGC803 cells before and after restoration of NKD2 expression (Figure 3A).

The colony formation assay was performed in BGC823 and MGC803 cells. The clone number was 153.3 \pm 18.1 vs. $88.3 \pm 25.8(P<0.05)$ in BGC823 cells and 126.0 \pm 11.1 vs. $59.3 \pm 21.0(P<0.05)$ in MGC803 cells before and after restoration of NKD2 expression (Figure 3B).

\section{NKD2 induced G2/M phase arrest and sensitized BGC823 and MGC803 cells to docetaxel}

Flow cytometry was employed to analyze the effects of NKD2 on the cell cycle. As shown in Figure $3 \mathrm{C}$, the distribution of cell phase in the NKD2 unexpressed and re-expressed BGC823 cell line was $45.81 \pm 0.11 \%$ vs. $41.48 \pm 0.02 \%$ in $\mathrm{G} 0 / \mathrm{G} 1$ phase, $43.94 \pm 0.12 \%$ vs. $44.82 \pm 0.02 \%$ in $\mathrm{S}$ phase, and $10.25 \pm 0.01 \%$ vs. $13.71 \pm 0.01 \%$ in $\mathrm{G} 2 / \mathrm{M}$ phase. The G2/M phase was significantly different before and after re-expression of NKD2 $(P<0.05)$. In MGC803 cells, the cell phase distribution was $43.20 \pm 0.03 \%$ vs. 41.86 $\pm 0.04 \%$ in $\mathrm{G} 0 / \mathrm{G} 1$ phase, $40.88 \pm 0.08 \%$ vs. $29.68 \pm$ $0.01 \%$ in $\mathrm{S}$ phase, and $17.98 \pm 0.02 \%$ vs. $30.26 \pm 0.03 \%$ in $\mathrm{G} 2 / \mathrm{M}$ phase before and after restoration of NKD2 expression. The G2/M phase was significantly different before and after re-expression of NKD2 in MGC803 cells $(P<0.01)$.

The role of NKD2 in cell cycle regulation was further validated by the detection of $\mathrm{G} 2 / \mathrm{M}$ phase related proteins. The expression of CyclinB1 and $\mathrm{Cdc} 2$ were dramatically reduced after re-expression of NKD2 in BGC823 and MGC803 cells, while the expression of CyclinD1 did not change before and after re-expression of NKD2. The effect of NKD2 on G2/M phase was further confirmed by the knocking down of NKD2 in SGC7901 cells. The expression levels of CyclinB1 and $\mathrm{Cdc} 2$ were increased after knockdown of NKD2 in SGC7901 cells (Figure 3D).

Docetaxel, a microtubule inhibitor, exerts its effects on the G2/M checkpoint. To determine whether NKD2 is involved in docetaxel sensitivity, we examined the cell viability of NKD2 unexpressed and reexpressed BGC823 and MGC803 cells after docetaxel treatment. The correlation of cell viability and docetaxel concentration was shown in Figure $3 \mathrm{E}$. The $\mathrm{IC}_{50}$ of docetaxel was $3.019 \pm 0.093$ vs. $1.761 \pm 0.054 \mathrm{ug} / \mathrm{ml}$ $(P<0.001)$ in BGC823 cells and $5.099 \pm 0.339$ vs. 1.433 $\pm 0.068 \mathrm{ug} / \mathrm{ml}(P<0.001)$ in MGC803 cells before and after restoration of NKD2 expression. These results indicate that NKD2 functions as a mitotic inhibitor in human gastric cancer cells and sensitizes these cells to docetaxel.

\section{Restoration of NKD2 expression inhibits cell invasion, migration and wound healing ability}

The transwell assay was employed to evaluate the effect of NKD2 on cell invasion in BGC823 and MGC803 cells. The number of invasive cells for each high power field under the microscope was $132.7 \pm 17.4$ vs. $70.0 \pm 18.1$ in BGC823 cells and $203.0 \pm 21.8$ vs. $98.3 \pm 17.2$ in MGC803 cells before and after restoration of NKD2 expression. The cell number was significantly different before and after re-expression of NKD2 in BGC823 and MGC803 cells $(P<0.01, P<0.05$, respectively). The effect of NKD2 on cell invasion was further validated by knocking down NKD2 in SGC7901 cells. The number of invasive cells was $148.0 \pm 15.5$ vs. $263.3 \pm 19.4$ before and after knockdown NKD2 in SGC7901 cells in each high power field under the microscope $(P<0.05$, Figure 4A).

Next, the transwell assay in the absence of ECM gel (extracellular matrix gel) coating was employed to explore the effect of NKD2 on cell migration in BGC823 and MGC803 cells. The number of migrated cells for each high power field under the microscope was $306.3 \pm 17.0$ vs. $166.0 \pm 32.5$ in BGC823 cells and $248.3 \pm 32.9$ vs. $119.0 \pm 17.3$ in MGC803 cells before and after restoration of NKD2 expression. The cell number was significantly different before and after re-expression of NKD2 (all $P<$ $0.05)$. The effect of NKD2 on cell migration was further validated by knocking down NKD2 in SGC7901 cells. The number of migrational cells for each high power field under the microscope was $137.3 \pm 15.9$ vs. $276.7 \pm 19.6$ before and after knockdown NKD2 in SGC7901 cells $(P<0.05$, Figure 4B).

The wound healing assay was also employed to measure the cell migration ability. As shown in Figure $4 \mathrm{C}$, the migration of BGC823 and MGC803 cells was apparently suppressed after re-expression of NKD2. And the migration ability of SGC7901 cells was promoted by knocking down NKD2. To further validate the effect of NKD2, the expression levels of MMP-2 and MMP-9 were detected by western blot. As shown in Figure 4D, the expression levels of MMP-2 and MMP-9 were reduced after re-expression of NKD2 in BGC823 and MGC803 cells. The inhibitory role of NKD2 in MMP-2 and MMP9 expression was further validated by the knocking down of NKD2 in SGC7901 cells. These results demonstrate that NKD2 suppresses gastric cancer cell invasion and migration.

\section{NKD2 suppresses gastric cancer cell growth in xenograft mice}

To further validate the effects of NKD2 in gastric cancer, NKD2 unexpressed and re-expressed BGC823 cell xenograft mouse models were employed (Figure 5A 

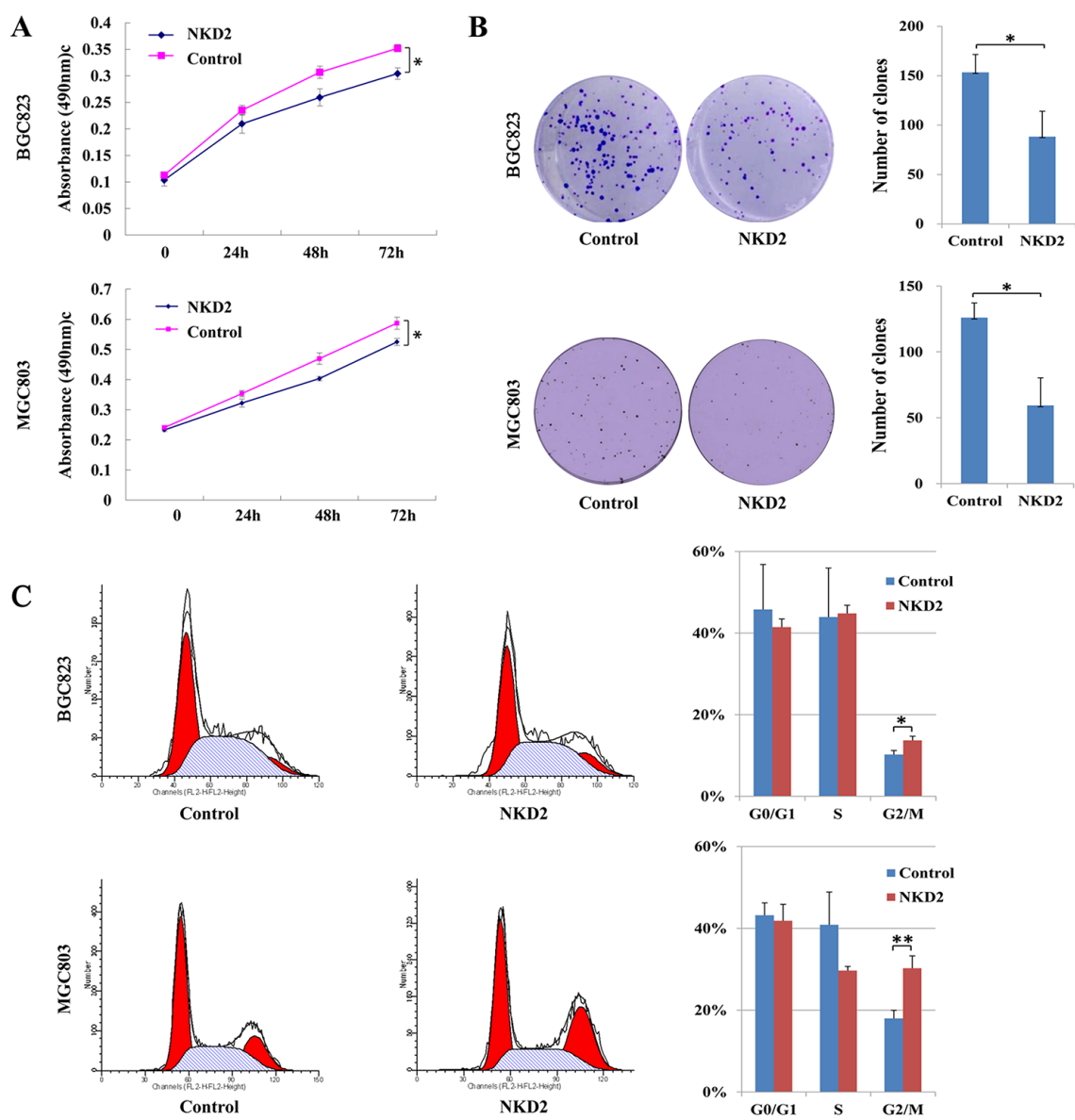

$\mathrm{D}$
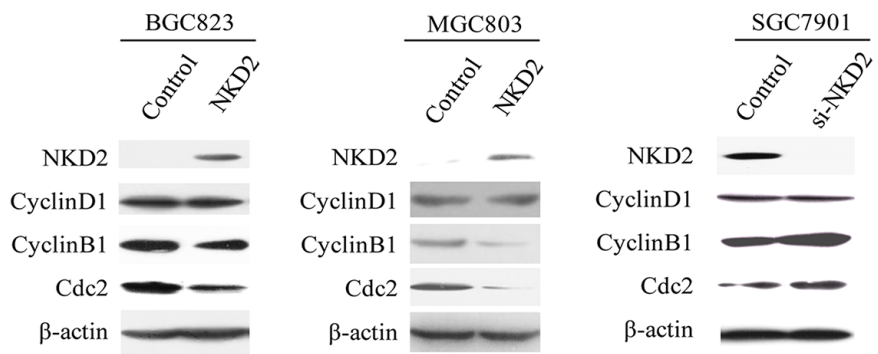

$\mathrm{E}$
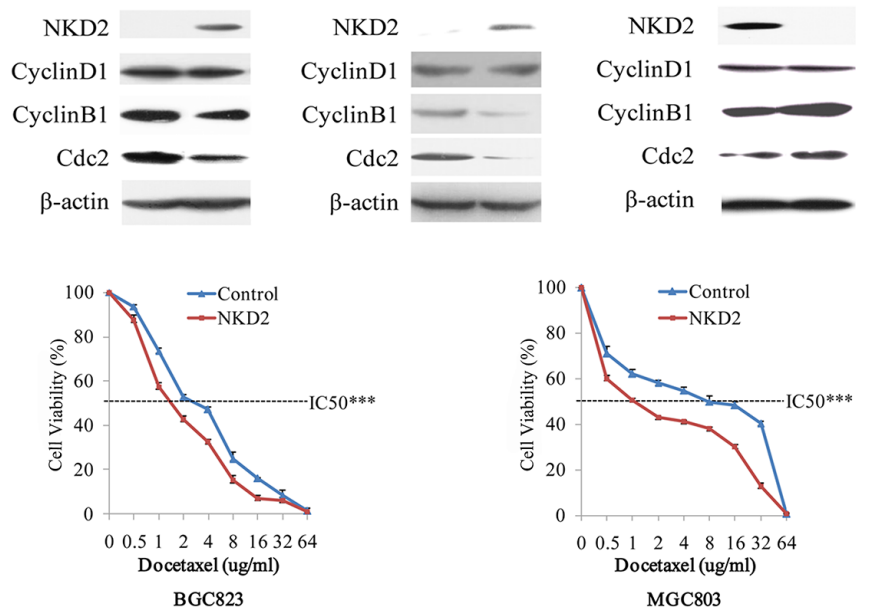

Figure 3: NKD2 induced G2/M phase arrest and sensitized BGC823 and MGC803 cells to docetaxel. A. Growth curves represent the cell viability analyzed by the MTT assay in NKD2 re-expressed and unexpressed BGC823 and MGC803 cells. Each experiment was repeated in triplicate. $* P<0.05$. B. Colony formation results show that colony number was reduced by re-expression of NKD2 in BGC823 and MGC803 cells. Each experiment was repeated in triplicate. Average number of tumor clones is represented by bar diagram. ${ }^{*} P<0.05$. C. Cell phase distribution in NKD2 unexpressed and re-expressed BGC823 and MGC803 cells. The ratio is presented by bar diagram. Each experiment was repeated for three times. ${ }^{*} P<0.05, * * P<0.01$. D. The expression of NKD2, CyclinD1, CyclinB1 and Cdc2 was detected by western blot in NKD2 unexpressed and re-expressed BGC823 and MGC803 cells. Knockdown of NKD2 in SGC7901 cells was used to validate the results. $\beta$-actin: internal control. E. The cell viability assay showed the effect of NKD2 on the sensitivity of BGC823 and MGC803 cells to docetaxel. $* * * P<0.001$. 
A
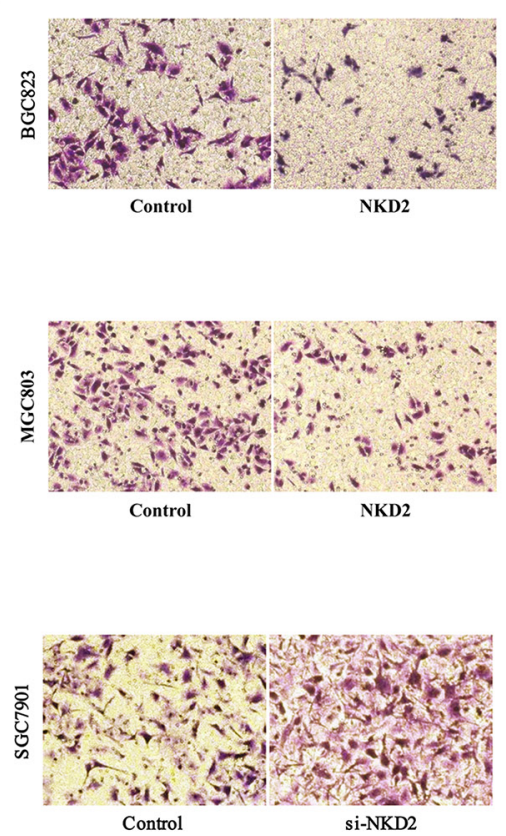

$\mathrm{C}$

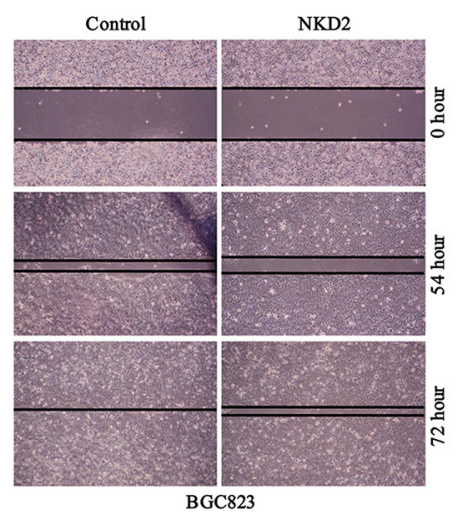

D

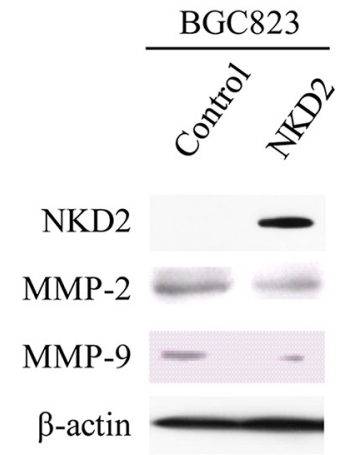

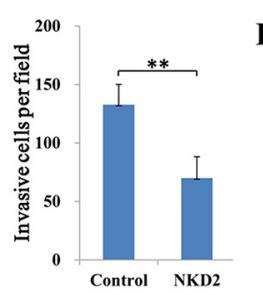

B
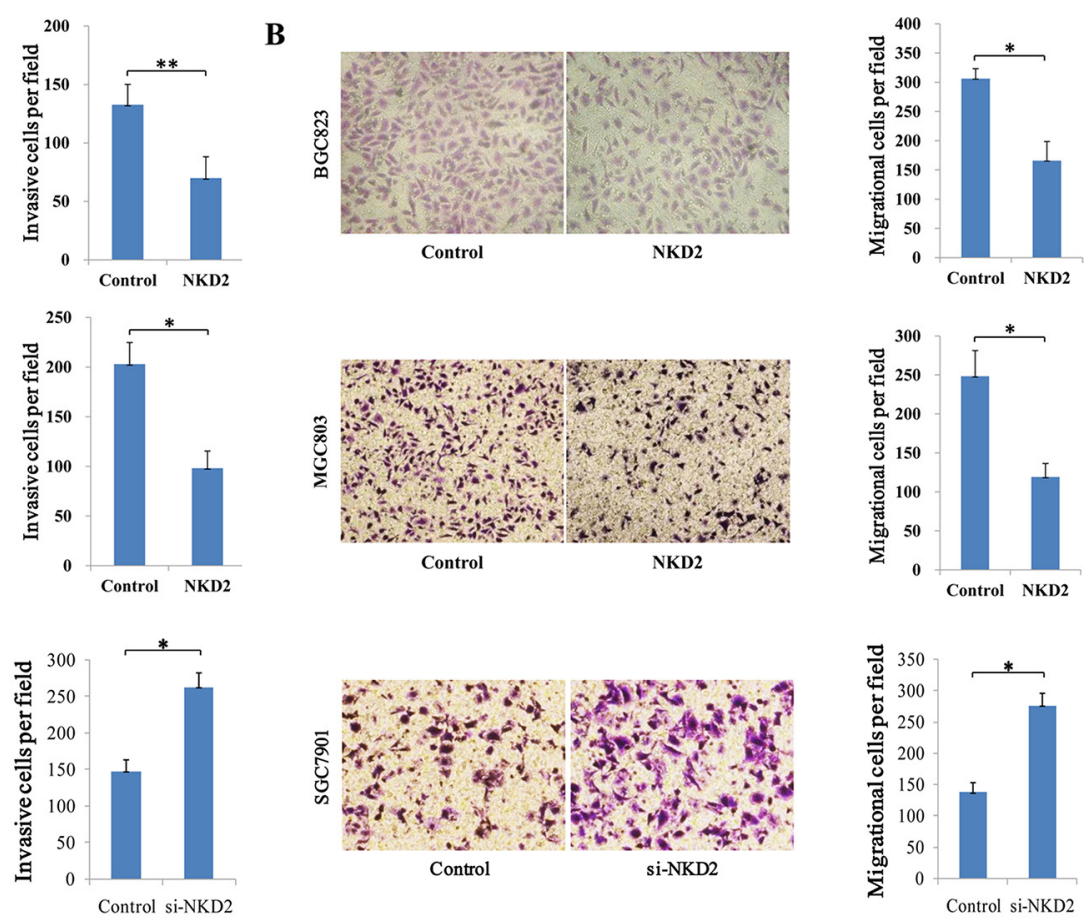

Control
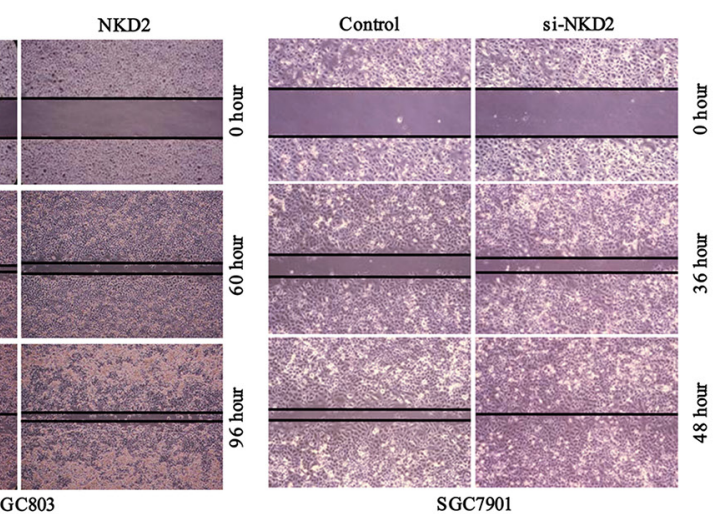

콩

言

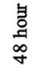

4: NKD2 inhibites cell invasion, migration and wound healing ability. A. Cell invasion in NKD2 unexpressed and expressed BGC823 and MGC803 cells, as well as cell invasion before and after knocking down NKD2 in SGC7901 cells. The invasive cell number is presented by bar diagram. Each experiment was repeated for three times. ${ }^{*} P<0.05, * * P<0.01$. B. Cell migration in NKD2 unexpressed and expressed BGC823 and MGC803 cells, as well as cell migration before and after knocking down NKD2 in SGC7901 cells. The migrational cell number is presented by bar diagram. Each experiment was repeated for three times. $* P<0.05$. C. Wound healing results in NKD2 unexpressed and expressed BGC823 and MGC803 cells, as well as the wound healing results before and after knockdown of NKD2 in SGC7901 cells. Each experiment was repeated for three times. D. The expression levels of NKD2, MMP-2 and MMP-9 were detected by western blot in NKD2 unexpressed and expressed BGC823 and MGC803 cells. Knockdown of NKD2 in SGC7901 cells was performed to validate these results. 
A

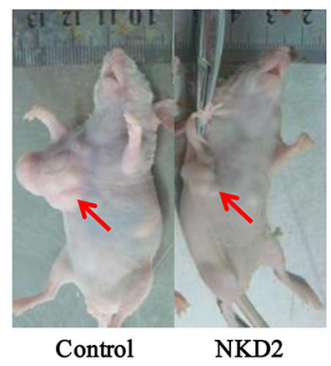

B

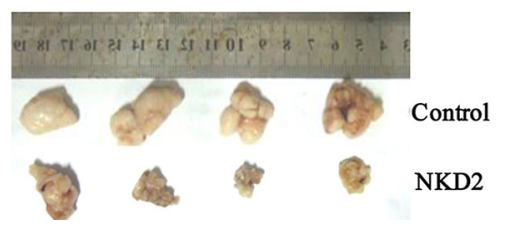

$\mathrm{C}$

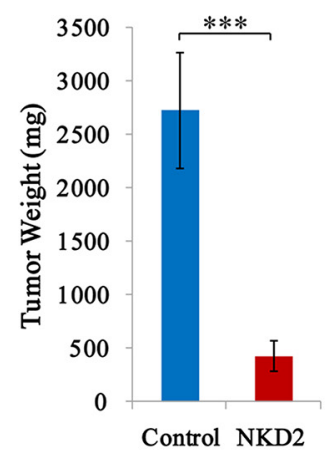

D

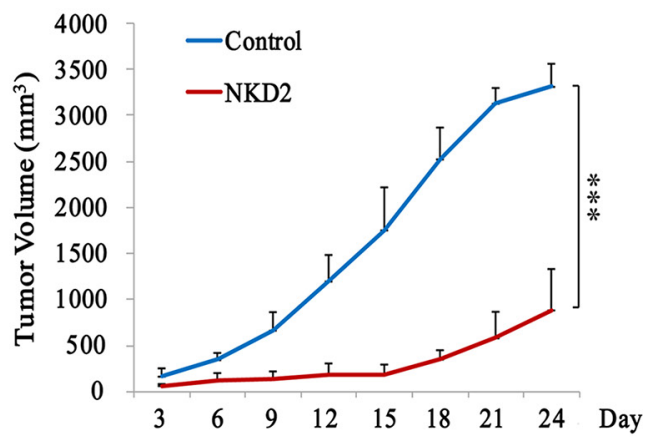

Figure 5: NKD2 suppresses gastric cancer cell growth in xenograft mice. A. Representative burdened nude mice in NKD2 expressed and unexpressed BGC823 cells. Red arrows show position of subcutaneous tumors. B. Representative xenografts in NKD2 re-expressed and unexpressed BGC823 cells. C. Tumor weight in nude mice at the 24th day after inoculation of NKD2 unexpressed and expressed BGC823 cells. Bars: mean of 4 mice. $* * * P<0.001$. D. The tumor volumes for NKD2 unexpressed and expressed BGC823 cell xenografts. Points: mean of 4 mice. ${ }^{* * *} P<0.001$.

and 5B). The xenograft tumor weight was $2727.0 \pm 541.6$ $\mathrm{mg}$ in NKD2 unexpressed BGC823 cell tumors and 427.6 $\pm 143.0 \mathrm{mg}$ in NKD2 re-expressed BGC823 cell tumors. The tumor weights were significantly different $(P<$ 0.001 , Figure 5C). The tumor volume was $3315.4 \pm 249.9$ $\mathrm{mm}^{3}$ in NKD2 unexpressed BGC823 cell xenografts and $890.2 \pm 448.3 \mathrm{~mm}^{3}$ in NKD2 re-expressed BGC823 cell xenografts. The tumor volumes were smaller in NKD2 reexpressed BGC823 cells compared to NKD2 unexpressed BGC823 cells $(P<0.001$, Figure 5D). These results suggest that NKD2 suppresses gastric cancer cell growth in vivo.

\section{NKD2 suppresses gastric cancer cell invasion and migration by down-regulating SOX18 expression}

NKD2 has been shown to negatively regulate canonical Wnt signaling through an interaction with Dishevelled. To explore the mechanism of NKD2 in gastric cancer, a Topflash reporter and TCF/LEF luciferase reporter assay were used in BGC823 cells. As shown in Figure 6A, relative luciferase activity was not changed after co-transfection of NKD2 with wild type or mutant type of $\beta$-catenin in BGC823 cells $(P>0.05)$ These data suggest that the activity of the TCF/LEF reporter was not affected by NKD2. The expression of Dvl-2, the NKD2 binding protein, was not changed before and after reexpression of NKD2 in BGC823 and MGC803 cells. No obvious Dvl-2 expression changes were found in SGC7901 cells before and after the knockdown of NKD2 (Figure 6E). These results demonstrate that NKD2 does not directly inhibit canonical Wnt signaling.
To further understand the mechanisms of NKD2 in gastric cancer progression, a gene expression array was employed. The gene expression profile was analyzed in NKD2 re-expressed and unexpressed BGC823 cells. Among a total of 31741 genes, expression changes were found in 1376 genes $(P<0.05)$. Among these genes, 43 genes were up-regulated and 167 genes were downregulated more than 2-fold (Figure 6B). DAVID software (http://david.abcc.ncifcrf.gov/home.jsp) was employed to obtain the disease related genes. Among these apparently changed genes, BCL2L11, LDB3, SOX18, BMP4, CR2, $D S C 2, H M G A 1, S F 3 B 4$ and TNFRSF1A were regarded as disease-related genes according to DAVID (Figure 6C). SOX18 was validated to be down-regulated by semiquantitative RT-PCR in NKD2 re-expressed BCG823 and MGC803 cells, and up-regulation of SOX18 was verified by the knocking down NKD2 in SGC7901 cells (Figure 6D). These results suggest that SOX18 is downregulated by NKD2 in human gastric cancer.

In human umbilical vein endothelial cells (HUVEC), metalloproteinase-7 (MMP-7) is up-regulated by SOX18, and confirmed that MMP-7 is a direct target of SOX18 [27]. In our study, the expression levels of SOX18 and MMP-2, 7, 9 were reduced in NKD2 reexpressed BGC823 and MGC803 cells. Up-regulation of SOX18 and MMP-2,7,9 was found after knockdown NKD2 in SGC7901 cells (Figure 6E). To further validate SOX18 is regulated by NKD2, we analyzed the association between SOX18 overexpression and NKD2 methylation in human primary gastric cancer. The expression of SOX18 was examined by IHC in 32 cases primary gastric cancer samples. The expression level of SOX18 is associated with NKD2 methylation 
significantly $(P<0.05$, Figure $6 \mathrm{~F})$. The results suggest that the expression of SOX18 is regulated by NKD2 in human primary gastric cancer.

To further validate that cell invasion and metastasis is induced by SOX18, siRNA knockdown technique was performed. As shown in Figure $6 \mathrm{G}$ and $6 \mathrm{H}$, the number of invasive cells is $384.3 \pm 14.8$ vs. $138.3 \pm 18.6$ in BGC 823 cells and $136.7 \pm 11.6$ vs. $86.0 \pm 14.5$ in MGC803 cells before and after knockdown SOX18 in each high power field (all $P<0.05$ ). And the number of migrational cells is $386.7 \pm 18.0$ vs. $153.0 \pm 18.7$ in BGC823 cells and $389.0 \pm 21.7$ vs. $146.0 \pm 17.3$ in MGC803 cells before and after knockdown SOX18 in each high power field (all $P<$ 0.05 ). The expression levels of MMP-2, 7, 9 were reduced after knockdown SOX18 in BGC823 and MGC803 cells (Figure 6I). Above results suggest that NKD2 impedes cell invasion and metastasis by inhibiting SOX18 in gastric cancer.

\section{DISCUSSION}

In this study, we detected the methylation status of NKD1 and NKD2 in human gastric cancer cell lines and primary cancer tissue samples. The expression levels of NKD1 and NKD2 were regulated by promoter region methylation. $N K D 1$ was infrequently methylated in primary gastric cancer, while NKD2 was frequently methylated. Methylation of NKD2 was related to cell differentiation, TNM stage, distant metastasis and overall survival, but no association was found between NKDI methylation and any of the analyzed clinical factors. Therefore, we mainly focused our study on NKD2 in gastric cancer. NKD2 inhibited cell proliferation, colony formation, and induced G2/M phase arrest. Re-expression of NKD2 sensitized gastric cancer cells to docetaxel. These results suggest that NKD2 methylation is involved in gastric cancer prognosis and metastasis. It may serve
A

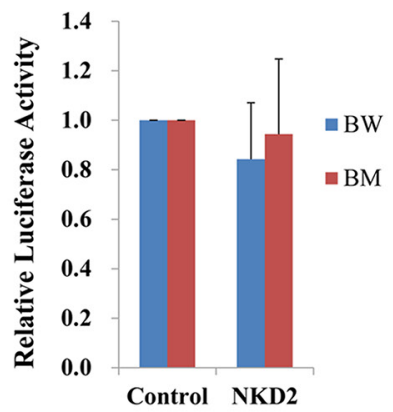

C

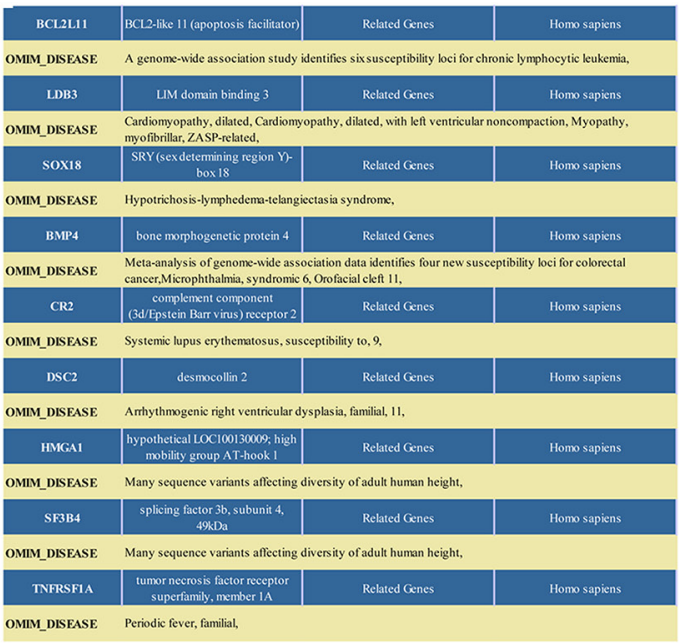

B

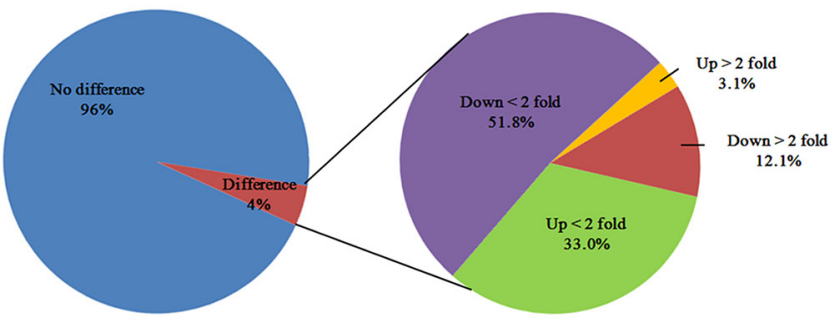

$\mathrm{D}$

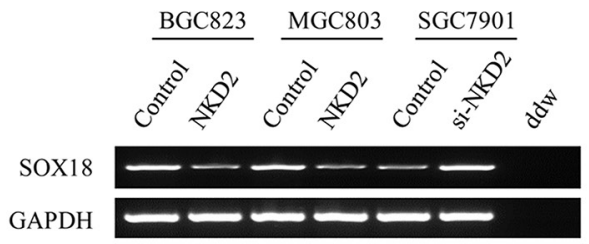

$\mathrm{E}$

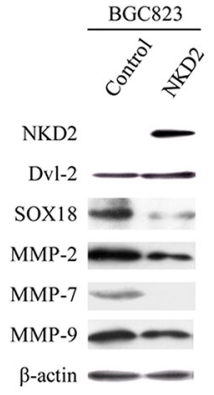

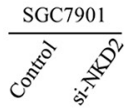

NKD2 -

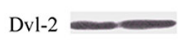

SOX18 -

MMP-2 -

MMP-7 -

MMP-9 - -

$\beta$-actin

Figure 6: NKD2 suppresses SOX18 and MMP-2,7,9 expression in gastric cancer. A. Results of TCF/LEF luciferase reporter assay. Relative luciferase activity (a ratio of firefly luciferase to renilla luciferase) was not changed after co-transfection of NKD2 with wild type or mutant type $\beta$-catenin in BGC823 cells $(P>0.05)$. The experiment was repeated three times. B. Gene expression array shows differentially expressed genes in NKD2 re-expressed and unexpressed BGC823 cells. The percentage of up-regulated or downregulated genes are shown in the pie chart. Angle of the sector: the percentage of each category. C. BCL2L11, LDB3, SOX18, BMP4, CR2, DSC2, HMGA1, SF3B4 and TNFRSF1A genes were associated with disease according to DAVID software (http://david.abcc.ncifcrf.gov/ home.jsp). D. The expression of SOX18 was detected by semi-quantitative RT-PCR in NKD2 unexpressed and re-expressed BGC823 and MGC803 cells. The results were further validated by knockdown of NKD2 in SGC7901 cells. E. The expression levels of NKD2, Dvl-2, SOX18 and MMP-2,7,9 were detected by western blot in NKD2 unexpressed and re-expressed BGC823 and MGC803 cells. The results were validated by knocking down NKD2 in SGC7901 cells. (Continued) 

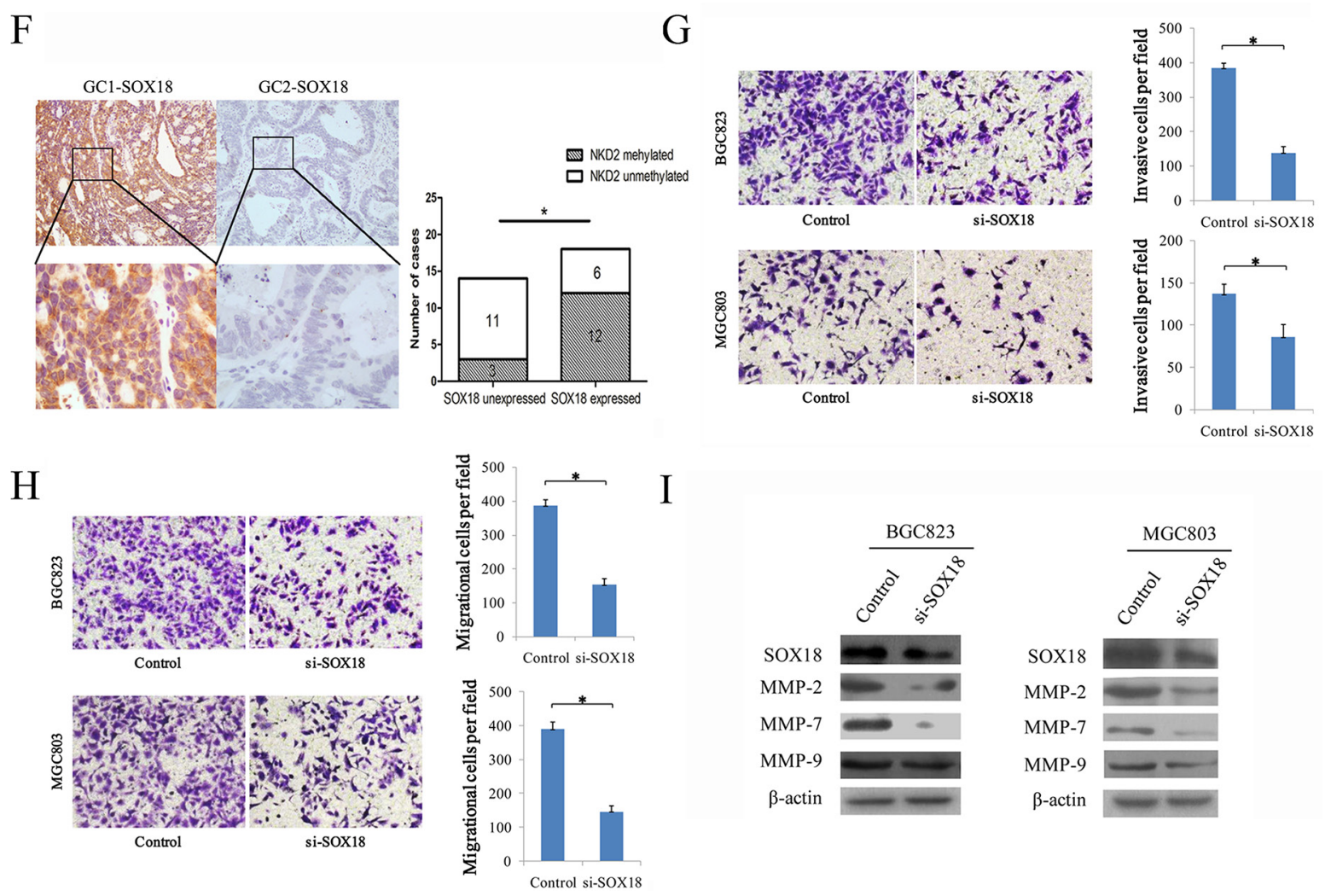

Control si-SOX18

Figure 6: (Continued) NKD2 suppresses SOX18 and MMP-2,7,9 expression in gastric cancer. F. Representative IHC results show SOX18 expression in primary gastric cancer (upper: $\times 100$; lower: $\times 400$ ). NKD2 is methylated in GC1 and unmethylated in GC2. The correlation of SOX18 expression and NKD2 methylation status is shown as a bar diagram. The expression of SOX18 is associated with NKD2 methylation significantly. GC: primary gastric cancer samples. ${ }^{*} P<0.05$. G. Cell invasion in BGC823 and MGC803 cells before and after knockdown SOX18. The invasive cell number is presented by bar diagram. Each experiment was repeated for three times. $* P<$ 0.05 . H. Cell migration in BGC823 and MGC803 cells before and after knockdown SOX18. The migrational cell number is presented by bar diagram. Each experiment was repeated for three times. ${ }^{*} P<0.05$. I. The expression levels of SOX18 and MMP-2,7,9 were detected by western blot before and after knockdown SOX18 in BGC823 and MGC803 cells.

as a gastric cancer diagnostic, prognostic and chemosensitive marker.

The role of NKD2 in gastric cancer progression and metastasis was further studied both in vitro and in vivo. The growth of gastric cancer xenografts was suppressed by NKD2. Cell invasion and migration was impeded by NKD2 in BGC823 and MGC803 cells. The mechanisms of NKD2 in gastric cancer cell invasion and migration were further investigated by detecting the expression of MMP-2 and MMP-9. The effect of NKD2 on the inhibition of MMP-2 and MMP-9 expression levels was revealed by re-expression of NKD2 in unexpressed cells, and this was further validated by knocking down NKD2 in highly expressed cells. By analyzing the gene expression profiles in NKD2 re-expressed and unexpressed BGC823 cells, 43 up-regulated and 167 down-regulated genes were found to be changed more than 2 fold. Among these genes, 9 were found to be related to disease according to DAVID software. Of these 9 genes, SOX18 has been reported to be related to cancer progression, invasion and metastasis in mouse and human cancers [28-30]. Down-regulation of SOX18 by NKD2 was validated by RT-PCR and western blot in gastric cancer cells. The expression of SOX18 is associated with NKD2 methylation significantly in primary gastric cancer. MMP-7 has been reported to be directly up-regulated by SOX18 [27]. We detected the expression of MMP-2,7,9 upon re-expression of NKD2 in unexpressed cells and knocking down of NKD2 in highly expressed cells. Down-regulation of SOX18 and MMP-2,7,9 by NKD2 was verified by both of these approaches. Further study found that SOX18 promotes cell invasion and metastasis by down regulating MMP$2,7,9$ in gastric cancer cells. All of the above results suggest that NKD2 suppresses gastric cancer progression and metastasis by down-regulation of SOX18.

In conclusion, $N K D 2$ is frequently methylated in human gastric cancer, and methylation of NKD2 is involved in gastric carcinogenesis. NKD2 methylation may serve as a gastric cancer diagnostic, prognostic and chemo-sensitive marker. NKD2 suppresses gastric cancer metastasis by down-regulating SOX18 and its downstream genes. 


\section{MATERIALS AND METHODS}

\section{Human tissue samples and cell lines}

Primary human gastric cancer cases (196) were collected from the Chinese PLA General Hospital in Beijing and the Ruijin Hospital in Shanghai. The median age of the cancer patients was 62 years old (range 20 87), and the ratio of males/females was 2.4:1. All cancer samples were classified according to TNM staging (AJCC 2010), including 17 cases of stage I, 51 cases of stage II, 101 cases of stage III and 27 cases of stage IV. The 5-years survival follow-up data were available for 77 cases. Twenty eight cases of normal gastric mucosa from patients without cancer were collected by endoscopy biopsy at the Chinese PLA General Hospital. All samples were collected following the guidelines approved by the institutional review board of the Chinese PLA General and Ruijin Hospitals with written informed consent from patients.

Six gastric cancer cell lines (SGC7901, MGC803, BGC823, AGS, N87, and MKN45) were previously established from primary gastric cancer and maintained in 90\% RPMI 1640 (Invitrogen, Carlsbad, CA) supplemented with $10 \%$ fetal bovine serum.

\section{5-aza-2'-deoxycytidine treatment}

Gastric cancer cell lines were split to a low density (30\% confluence) 12 hours before treatment. Cells were treated with 5-aza-2'-deoxycytidine (DAC) (Sigma, St. Louis, MO) at a concentration of $2 \mu \mathrm{M}$. Growth medium conditioned with DAC at a concentration of $2 \mu \mathrm{M}$ was exchanged every 24 hours for a total of 96 hours of treatment.

\section{RNA isolation and semi-quantitative RT-PCR}

Total RNA was isolated by Trizol reagent (Life Technologies, Gaithersburg, MD). First strand cDNA was synthesized according to the manufacturer's instructions (Invitrogen, Carlsbad, CA). PCR primers for NKD1 and NKD2 are listed in Supplementary Table S1. The primer sets for NKD1 and NKD2 were designed to span intronic sequences between adjacent exons in order to control for genomic DNA contamination. RT-PCR was amplified for 33 cycles. GAPDH was used as an internal control.

\section{Bisulfite modification, methylation-specific PCR (MSP) and bisulfite sequencing}

DNA was prepared by the proteinase $\mathrm{K}$ method. Bisulfite treatment was carried out as previously described [31]. MSP primers were designed according to genomic sequences around transcription start sites (TSS) and synthesized to detect unmethylated (U) and methylated (M) alleles. Bisulfite sequencing (BSSQ) was performed as previously described [32]. BSSQ products were amplified by primers flanking the targeted regions including MSP products. All primers are listed in Supplementary Table S1.

\section{Immunohistochemistry}

Immunohistochemistry (IHC) was performed in primary gastric cancer samples and paired adjacent tissue samples. The NKD2 antibody was diluted 1:500 (Novus Biology, CO, USA) and the SOX18 antibody was diluted 1:1000(LifeSpan BioSciences, Inc, WA, USA). The staining intensity and extent of the staining area were scored using the German semi-quantitative scoring system as previously described $[32,33]$.

\section{Construction of NKD2 expression vector and transfection assay}

Full-length NKD2 cDNA (GenBank accession number NM_033120) was cloned into the pCMV6 vector. Transient transfection was performed using Lipofectamine 2000 (Intrivogen, Carlsbad, CA) or FuGENE HD (Roche Applied Science, Indianapolis, IN) according to the manufacturer's instructions.

\section{Cell viability detection}

Cells were plated into 96-well plates at $2 \times 10^{3}$ cells/ well, and the cell viability was measured by the MTT assay (KeyGEN Biotech, Nanjing, China) at 0, 24, 48 and $72 \mathrm{~h}$. Absorbance was measured on a microplate reader (Thermo Multiskan MK3, MA, USA) at a wavelength of $490 \mathrm{~nm}$.

The sensitivity of gastric cancer cells to docetaxel was analyzed by detecting the cell viability in NKD2 unexpressed or re-expressed cells treated by docetaxel at $0,0.5,1,2,4,8,16,32$ and $64 \mathrm{ug} / \mathrm{ml}$ for 48 hours. The $\mathrm{IC}_{50}$ was defined as the concentration required for $50 \%$ inhibition of cell growth. Absorbance was measured as specified above. The percentage of viable cells was calculated as follows: $(\%)=[\mathrm{A} 490($ treated $)-\mathrm{A} 490$ (blank) $] /$ [A490(control)-A490(blank)] × 100\%.

\section{Colony formation assay}

NKD2 unexpressed and re-expressed BGC823 and MGC803 cells were seeded at 500 cells/well in 6-well plates in triplicate. Growth medium conditioned with G418 (Invitrogen, Carlsbad, CA) at $450 \mu \mathrm{g} / \mathrm{ml}$ was exchanged every 24 hours. Clones were counted 14 days after being fixed with $75 \%$ ethanol and stained with $0.2 \%$ crystal violet (Beyotime, Nanjing, China) for visualization and counting.

\section{Flow cytometry}

Cells were starved 12 hours for synchronization, and the cells were re-stimulated with $10 \%$ FBS for 24 hours. 
Cells were fixed with $70 \%$ ethanol and treated using the Cell Cycle Detection Kit (KeyGenBiotech, Nanjing, China). The cells were then sorted by a FACS Caliber flow cytometer (BD Biosciences, Mansfield, CA). The cell phase distribution was analyzed by the Modfit software (Verity Software House, ME, USA).

\section{Transwell assay}

Cells were suspended in serum-free medium. Cells $\left(2 \times 10^{4}\right)$ were placed into the upper chamber of an 8 $\mu \mathrm{m}$ pore size Transwell apparatus (Corning, NY, USA) and incubated for 18 hours. Cells that migrated to the lower surface of the membrane were stained with crystal violet and counted in three independent high-power fields $(\times 200)$. For invasion analysis, cells $\left(2 \times 10^{4}\right)$ were seeded into the upper chamber of a transwell apparatus coated with Matrigel (BD Biosciences, San Jose, CA) and incubated for 36 hours. Cells that invaded into the lower membrane surface were stained with crystal violet and counted in three independent high-power fields $(\times 200)$.

\section{Wound healing assay}

Creation of a linear scratch wound was performed using a pipette tip in a confluent monolayer of cells in 6-well plates. Medium without FBS was used in order to inhibit cell proliferation.

\section{siRNA knockdown technique}

Selected siRNAs targeting NKD2, siRNAs targeting SOX18 and the RNAi negative control duplex were used in this study. The sequences of the siRNAs are listed in Supplementary Table S1. The RNAi oligonucleotide and RNAi negative control duplex were transfected into NKD2 highly expressing SGC7901 cells or SOX18 expressing BGC823 cells and MGC803 cells.

\section{Luciferase reporter assay}

Top flash reporter and TCF/LEF reporter luciferase reporter assay was employed in BGC823 cells as previously described [34]. Relative luciferase activity (a ratio of firefly luciferase to renilla luciferase) after cotransfection of NKD2 with wild type or mutant type of $\beta$-catenin in BGC823 cells was measured by the Dual Luciferase Reporter Assay system (Promega, Shanghai, China).

\section{Gene expression array}

Total RNA was isolated from NKD2 re-expressed and unexpressed BGC823 cells by Trizol reagent (Life Technologies, Gaithersburg, MD) as previously described. The RNA samples were labeled with $\mathrm{Cy} 5 /$
Cy3 and hybridized to the Human Whole Genome One Array (Phalanx Biotech Group, CA, USA). The hybridized chips were scanned by an Axon 4000 scanner (Molecular Devices, CA, USA). Spot quantification was performed using the Genepix 4.1 software (Axon Instruments, CA, USA). Differentially expressed genes with fold changes $>2$ were further analyzed by DAVID bioinformatics (LIB, SAIC-Frederick, Inc., Frederick, MD).

\section{Western blot}

Protein from gastric cancer cells was collected 48 hours after transfection and western blot was performed as described previously [35]. Antibodies were diluted according to manufacturer's instructions. The primary antibodies were as follows: NKD2, Dvl-2 (CST, MA, USA), MMP-2, MMP-9, CyclinD1, CyclinB1, Cdc2, MMP-7 (Bioworld Tech, MN, USA), SOX18 (Abcam, MA, USA), and $\beta$-actin (Beyotime Biotech., China).

\section{NKD2 re-expressed and unexpressed BGC823 cell xenograft mouse model}

NKD2 re-expressed or unexpressed BGC823 cells $\left(2 \times 10^{6}\right)$ were suspended in $0.1 \mathrm{ml} \mathrm{PBS}$ and injected subcutaneously into the right armpit of each 4-week-old female Balb/c nude mouse (6 per group). The diameter of the tumors was measured every 3 days. Tumor volume $\left(\mathrm{mm}^{3}\right)$ was estimated by the following formula: tumor volume $=($ length $) \times(\text { width })^{2} / 2$. Mice were sacrificed at 24 days, and tumor size and weight were measured after dissection. All procedures were approved by the Animal Ethics Committee of the Chinese PLA General Hospital.

\section{Statistical analysis}

SPSS 17.0 software (IBM, NY, USA) was used for data analysis. The student's $t$ test, the Pearson chi-squared test, the Fisher's exact test and the log-rank test (KaplanMeier) and COX regression analysis were used in this study. $P<0.05$ was regarded as a statistically significant difference.

\section{ACKNOWLEDGMENTS AND FUNDING}

This work was supported by the following grants: National Basic Research Program of China (973 Program No. 2012CB934002, 2015CB553904); National High-tech R\&D Program of China (863 Program No. SS2012AA020314, SS2012AA020821, SS2012AA020303); National Key Scientific Instrument Special Programme of China (Grant No. 2011YQ03013405); National Science Foundation of China (NSFC No.81402345, 81121004, 81161120432, 81490753 and 81401950); Tianjin Research Program 
of Application Foundation \& Advanced Technology (No.14JCQNJC12400); and the Science and Technology Development Program of Tianjin High School (Grant No. 20120115).

\section{CONFLICTS OF INTEREST}

James G. Herman is a consultant to MDxHealth. The other authors declare no conflict of interest.

\section{Author contributions}

YJ and $\mathrm{BC}$ performed experiments, analyzed data and wrote the manuscript. YY, EL, QZ, YL and YY provided feedback and experimental advice. JGH provided experimental advice and manuscript editing. MG conceived the study design, supervised the experiments and edited the manuscript. All authors approved the final version of the submitted manuscript.

\section{Editorial note}

This paper has been accepted based in part on peerreview conducted by another journal and the authors' response and revisions as well as expedited peer-review in Oncotarget.

\section{REFERENCES}

1. Ferlay J, Soerjomataram I, Dikshit R, Eser S, Mathers C, Rebelo M, Parkin DM, Forman D, Bray F. Cancer incidence and mortality worldwide: sources, methods and major patterns in GLOBOCAN 2012. Int J Cancer. 2015; 136:E359-386.

2. Liang H, Kim YH. Identifying molecular drivers of gastric cancer through next-generation sequencing. Cancer Lett. 2013; 340:241-246.

3. Zheng L, Wang L, Ajani J, Xie K. Molecular basis of gastric cancer development and progression. Gastric Cancer. 2004; 7:61-77.

4. Resende C, Thiel A, Machado JC, Ristimaki A. Gastric cancer: basic aspects. Helicobacter. 2011; 16:38-44.

5. Hartgrink HH, Jansen EP, van Grieken NC, van de Velde CJ. Gastric cancer. Lancet. 2009; 374:477-490.

6. Guilford PJ, Hopkins JB, Grady WM, Markowitz SD, Willis J, Lynch H, Rajput A, Wiesner GL, Lindor NM, Burgart LJ, Toro TT, Lee D, Limacher JM, et al. E-cadherin germline mutations define an inherited cancer syndrome dominated by diffuse gastric cancer. Hum Mutat. 1999; 14:249-255.

7. Barber M, Murrell A, Ito Y, Maia AT, Hyland S, Oliveira C, Save V, Carneiro F, Paterson AL, Grehan N, Dwerryhouse S, Lao-Sirieix P, Caldas C, et al. Mechanisms and sequelae of E-cadherin silencing in hereditary diffuse gastric cancer. J Pathol. 2008; 216:295-306.
8. Li-Chang HH, Kasaian K, Ng Y, Lum A, Kong E, Lim H, Jones S, Huntsman DG, Schaeffer DF, Yip S. Retrospective review using targeted deep sequencing reveals mutational differences between gastroesophageal junction and gastric carcinomas. BMC Cancer. 2015; 15:32.

9. $\mathrm{Hu}$ XT, He C. Recent progress in the study of methylated tumor suppressor genes in gastric cancer. Chin J Cancer. $2013 ; 32: 31-41$.

10. Sato F, Meltzer SJ. CpG island hypermethylation in progression of esophageal and gastric cancer. Cancer. 2006; 106:483-493.

11. Tamura G. Alterations of tumor suppressor and tumor-related genes in the development and progression of gastric cancer. World J Gastroenterol. 2006; 12:192-198.

12. Guo M, Yan W. Epigenetics of gastric cancer. Methods Mol Biol. 2015; 1238:783-799.

13. Hu T, Krezel AM, Li C, Coffey RJ. Structural studies of human Naked2: a biologically active intrinsically unstructured protein. Biochem Biophys Res Commun. 2006; 350:911-915.

14. Yan D, Wallingford JB, Sun TQ, Nelson AM, Sakanaka C, Reinhard C, Harland RM, Fantl WJ, Williams LT. Cell autonomous regulation of multiple Dishevelled-dependent pathways by mammalian Nkd. Proc Natl Acad Sci U S A. 2001; 98:3802-3807.

15. Argos M, Kibriya MG, Jasmine F, Olopade OI, Su T, Hibshoosh H, Ahsan H. Genomewide scan for loss of heterozygosity and chromosomal amplification in breast carcinoma using single-nucleotide polymorphism arrays. Cancer Genet Cytogenet. 2008; 182:69-74.

16. Huang Y, Bove B, Wu Y, Russo IH, Yang X, Zekri A, Russo J. Microsatellite instability during the immortalization and transformation of human breast epithelial cells in vitro. Mol Carcinog. 1999; 24:118-127.

17. Sheu JC, Lin YW, Chou HC, Huang GT, Lee HS, Lin YH, Huang SY, Chen CH, Wang JT, Lee PH, Lin JT, Lu FJ, Chen DS. Loss of heterozygosity and microsatellite instability in hepatocellular carcinoma in Taiwan. Br J Cancer. 1999; 80:468-476.

18. Lu Y, Yu Y, Zhu Z, Xu H, Ji J, Bu L, Liu B, Jiang H, Lin Y, Kong $\mathrm{X}, \mathrm{Hu} \mathrm{L}$. Identification of a new target region by loss of heterozygosity at $5 \mathrm{p} 15.33$ in sporadic gastric carcinomas: genotype and phenotype related. Cancer Lett. 2005; 224:329-337.

19. Xu SF, Peng ZH, Li DP, Qiu GQ, Zhang F. Refinement of heterozygosity loss on chromosome $5 \mathrm{p} 15$ in sporadic colorectal cancer. World J Gastroenterol. 2003; 9:1713-1718.

20. Katoh M. Molecular cloning, gene structure, and expression analyses of NKD1 and NKD2. Int J Oncol. 2001; 19:963-969.

21. Van Raay TJ, Coffey RJ, Solnica-Krezel L. Zebrafish Naked 1 and Naked 2 antagonize both canonical and noncanonical Wnt signaling. Dev Biol. 2007; 309:151-168. 
22. Li C, Franklin JL, Graves-Deal R, Jerome WG, Cao Z, Coffey RJ. Myristoylated Naked2 escorts transforming growth factor alpha to the basolateral plasma membrane of polarized epithelial cells. Proc Natl Acad Sci U S A. 2004; 101:5571-5576.

23. Ding W, Li C, Hu T, Graves-Deal R, Fotia AB, Weissman AM, Coffey RJ. EGF receptor-independent action of TGFalpha protects Naked2 from AO7-mediated ubiquitylation and proteasomal degradation. Proc Natl Acad Sci U S A. 2008; 105:13433-13438.

24. Zhao S, Kurenbekova L, Gao Y, Roos A, Creighton CJ, Rao P, Hicks J, Man TK, Lau C, Brown AM, Jones SN, Lazar AJ, Ingram D, et al. NKD2, a negative regulator of Wnt signaling, suppresses tumor growth and metastasis in osteosarcoma. Oncogene. 2015; 34:5069-5079.

25. Griffiths EA, Gore SD. DNA methyltransferase and histone deacetylase inhibitors in the treatment of myelodysplastic syndromes. Semin Hematol. 2008; 45:23-30.

26. Qin T, Jelinek J, Si J, Shu J, Issa JP. Mechanisms of resistance to 5-aza-2'-deoxycytidine in human cancer cell lines. Blood. 2009; 113:659-667.

27. Hoeth M, Niederleithner H, Hofer-Warbinek R, Bilban M, Mayer H, Resch U, Lemberger C, Wagner O, Hofer E, Petzelbauer P, de Martin R. The transcription factor SOX18 regulates the expression of matrix metalloproteinase 7 and guidance molecules in human endothelial cells. PLoS One. 2012; 7:e30982.

28. Duong T, Proulx ST, Luciani P, Leroux JC, Detmar M, Koopman P, Francois M. Genetic ablation of SOX18 function suppresses tumor lymphangiogenesis and metastasis of melanoma in mice. Cancer Res. 2012; 72:3105-3114.
29. Jethon A, Pula B, Olbromski M, Werynska B, Muszczynska-Bernhard B, Witkiewicz W, Dziegiel P, Podhorska-Okolow M. Prognostic significance of SOX18 expression in non-small cell lung cancer. Int J Oncol. 2015; 46:123-132.

30. Pula B, Olbromski M, Wojnar A, Gomulkiewicz A, Witkiewicz W, Ugorski M, Dziegiel P, PodhorskaOkolow M. Impact of SOX18 expression in cancer cells and vessels on the outcome of invasive ductal breast carcinoma. Cell Oncol (Dordr). 2013; 36:469-483.

31. Herman JG, Graff JR, Myohanen S, Nelkin BD, Baylin SB. Methylation-specific PCR: a novel PCR assay for methylation status of CpG islands. Proc Natl Acad Sci U S A. 1996; 93:9821-9826.

32. Jia Y, Yang Y, Liu S, Herman JG, Lu F, Guo M. SOX17 antagonizes WNT/beta-catenin signaling pathway in hepatocellular carcinoma. Epigenetics. 2010; 5:743-749.

33. Yan W, Wu K, Herman JG, Brock MV, Fuks F, Yang L, Zhu H, Li Y, Yang Y, Guo M. Epigenetic regulation of DACH1, a novel Wnt signaling component in colorectal cancer. Epigenetics. 2013; 8:1373-1383.

34. Jia Y, Yang Y, Brock MV, Zhan Q, Herman JG, Guo M. Epigenetic regulation of DACT2, a key component of the Wnt signalling pathway in human lung cancer. J Pathol. 2013; 230:194-204.

35. Jia Y, Yang Y, Brock MV, Cao B, Zhan Q, Li Y, Yu Y, Herman JG, Guo M. Methylation of TFPI-2 is an early event of esophageal carcinogenesis. Epigenomics. 2012; 4:135-146. 